\title{
Highly Efficient and Enantioselective Silylation of Alcohols
}

Organo- and

Biocatalysis

Key words

silylation

part-per-million

catalysis

kinetic resolution

desymmetrization

alcohols<smiles>C[C@@H](O)c1ccccc1</smiles><smiles>COC(C)c1ccccc1</smiles>

18 examples

er from $84: 16$ to $>99: 1$

$s$-factors from 21 to 132

Selected examples:<smiles>CC(O)c1ccccc1</smiles>

$55 \%$ conversion er of $(R)-1=99: 1$ er of $(S)-2=91: 9$ $s=43$<smiles>CC(O)c1ccccc1Cl</smiles>

$53 \%$ conversion er of $(R)-1>99: 1$ er of $(S)-2=95: 5$ $s=127$<smiles>C[C@H](O)c1ccc(C(F)(F)F)cc1</smiles>

$54 \%$ conversion er of $(R)-1>99: 1$ er of $(S)-2=93: 7$ $s=98$<smiles>COc1ccc([C@@H](C)O)cc1</smiles>

$54 \%$ conversion er of $(R)-1=97: 3$ er of $(S)-2=91: 9$ $s=35$

(b) Desymmetrization of meso-diols:<smiles>[R]c1ccccc1C(O)C(O)c1ccccc1P</smiles>

$\mathrm{R}=\mathrm{H}, \mathrm{Me}, \mathrm{OMe}$

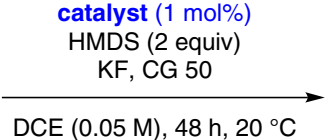

DCE $(0.05 \mathrm{M}), 48 \mathrm{~h}, 20^{\circ} \mathrm{C}$

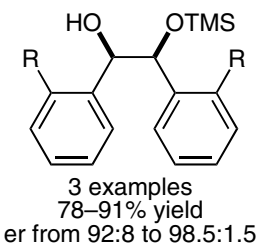

Significance: The Song group reports an asymmetric silylation of secondary alcohols catalyzed by a BINOL-derived polyether. By using HMDS as the silylating reagent, the authors were able to apply their developed catalytic system to kinetic resolution of secondary alcohols at a catalyst loading of $1 \mathrm{ppm}$. The system was also applied to the desymmetrization of meso-diols. Silylation of the catalyst is the predominant deactivation pathway. However, desilylation of this species is faster than that of the desired silylated products, thereby permitting regeneration of the catalytically active species through desilylation and subsequent protonation.

SYNFACTS Contributors: Benjamin List, Grigory A. Shevchenko Synfacts 2015, 11(9), 0985 Published online: 18.08.2015 DOI: 10.1055/s-0035-1560062; Reg-No.: B07315SF
Comment: Only a handful of reported organocatalytic reactions having high turnover numbers (TONs) are known (for a recent report with a TON $>10^{5}$, see: Angew. Chem. Int. Ed. 2014, 53, 8765). Song and co-workers contribute impressively to this field by presenting a catalytic system with TONs of up to $10^{6}$. For the first catalytic asymmetric silylation of alcohols with HMDS, see: Synlett 2015, 26, 1093. 